\title{
Avaliação de híbridos duplos de pimentão
}

\section{Sally Ferreira Blat ${ }^{1}$; Leila Trevizan Braz ${ }^{2}$; Alcione da Silva Arruda ${ }^{3}$.}

${ }^{1}$ APTA Regional Centro Leste, C. postal 271, 14001-970 Ribeirão Preto-SP; ${ }^{2}$ UNESP-FCAV, Produção Vegetal, Via de acesso Prof. Paulo Donato Castellane, km 5, 14870-000 Jaboticabal-SP; ${ }^{3}$ UEGoiás; sally@aptaregional.sp.gov.br; leilatb@fcav.unesp.br; alcionearruda@terra.com.br

\section{RESUMO}

Obteve-se híbridos duplos de pimentão, os quais foram avaliados por estimativa da heterose em relação à média dos progenitores, ao progenitor superior e ao híbrido padrão. Dez híbridos duplos foram obtidos em casa de vegetação a partir de cruzamentos entre cinco híbridos simples, Magali R (híbrido padrão), BGJ-27, BGJ28, BGJ-29 e BGJ-30. O delineamento experimental adotado foi de blocos casualizados, com três repetições e 15 tratamentos, sendo cinco híbridos simples e dez híbridos duplos. Foram avaliados o número de dias para o florescimento, peso de frutos, produção de frutos $/ \mathrm{m}^{2}$, comprimento e largura de frutos, número de lóculos, espessura de polpa, firmeza de frutos e altura da planta. O híbrido simples BGJ-27 obteve melhor desempenho em número de dias para o florescimento (mais precoce), peso médio do fruto, largura do fruto, espessura de polpa e firmeza do fruto. Dentre os híbridos duplos, o BGJ-28 x BGJ-30 mostrou-se superior em número de dias para o florescimento (mais precoce), espessura de polpa e número de lóculos. Os híbridos simples, BGJ-27 e Magali R (híbrido padrão) e os duplos, BGJ-27 x BGJ-29 e BGJ-27 x BGJ-28 apresentaram maior produção e peso médio de frutos, características de maior interesse do produtor. Entre os caracteres avaliados, a utilização de híbridos duplos para produção pode ser promissora, dependendo dos custos de produção e da qualidade dos frutos dos diversos híbridos.

\section{ABSTRACT}

\section{Evaluation of sweet pepper double hybrids}

The purpose of this work was to obtain sweet pepper double hybrids and evaluate them through a heterosis estimation of the mean parent, best parent, and the standard hybrid. Ten double hybrids were obtained in a greenhouse from crossings of five simple hybrids. The statistical analysis of data was performed using a randomized block design with three replications and fifteen treatments, consisting of five simple hybrids and ten double hybrids. Evaluations included the number of days to flowering, fruit weight, fruit yield $/ \mathrm{m}^{2}$, fruit length and girth, number of locules, flesh thickness, fruit firmness, and plant height. Simple hybrid BGJ-27 showed the best performance in number of days to flowering, fruit weight, fruit girth, flesh thickness, and fruit firmness, while double hybrids BGJ-28 x BGJ30 were superior for number of days to flowering, flesh thickness, and number of locules. With regard to the most interesting characters for the producer, that is, fruit yield and weight, BGJ-27 and Magali $\mathrm{R}$ showed the best performance among the simple hybrids, while BGJ-27 x BGJ-29 and BGJ-27 x BGJ-28 showed the best performance among the double hybrids. In general, considering the evaluated characters, the production of double hybrids proved to be promising in this study.

Keywords: Capsicum annuum L., heterosis, hybrids.

Palavras-chave: Capsicum annuum L., heterose, híbridos.

\section{(Recebido para publicação em 18 de janeiro de 2006; aceito em 3 de julho de 2007)}

$\mathrm{O}$ pimentão está entre as dez hortaiças mais consumidas no Brasil e no mundo. Estima-se que dos 13 mil ha de área cultivada no Brasil, 1.000 ha sejam destinados ao cultivo protegido. $\mathrm{O}$ mercado de sementes de pimentão no Brasil, é estimado em US\$ 3 milhões/ ano; dos quais, US\$ 600 a 900 mil estão relacionados ao segmento de pimentão cultivado em estufa. A distribuição do plantio concentra-se na região Sudeste, sendo que o estado de São Paulo destaca-se como o maior produtor, com 8.291 ha, produzindo 70 mil t e gerando 4.543 empregos (CNPH, 2001).

Devido às mudanças requeridas pelo mercado e as exigências do consumidor, o melhoramento desta hortaliça vem priorizando não apenas a produtividade, mas também a qualidade do produto. Por conseguinte, os principais objetivos têm sido a obtenção de frutos uniformes e com alta qualidade, polpa grossa, plantas precoces e resistentes a patógenos e pragas. Assim sendo, o uso de híbridos vem sendo cada vez mais empregado devido às suas vantagens, como a maior resistência a pragas e doenças, maior uniformidade, vigor de planta, homeostase, maturação precoce, aumento da qualidade e do rendimento e patente natural, que garante o retorno do investimento (Miranda \& Casali, 1988).

O sucesso do desempenho de um híbrido está na sua heterose, que é a manifestação do vigor para caracteres de interesse na geração $\mathrm{F}_{1}$, em comparação com os genitores. Dentre os caracteres nos quais ocorre maior expressão de vigor híbrido, os componentes de rendimento têm sido os mais estudados. Como exemplo, Tavares \& Maluf (1994) e Innecco (1995) verificaram a superioridade de híbridos em pimentão, quando comparados com a cultivar padrão para produção total de frutos, apresentando valores máximos de $26,10 \%$ e $39,45 \%$ respectivamente; para número total de frutos, valores máximos de 7,10\% e 22,53\%; para número de frutos precoces, valores de heterose de $21,00 \%$ e $70,65 \%$; peso médio de frutos de $19,70 \%$ e 49,64\%; e peso médio de fruto precoce com valores máximo de heterose de 39,60\% e 42,58\% respectivamente.

Ahmed \& Muzafar Hurra (2000), Doshi \& Shukla (2000) e Kumar \& Lal (2001) constataram magnitudes percentuais de 43,31\%, 24,23\% e $12,45 \%$, respectivamente, de heterobeltiose para o caráter altura de planta, em pimentão. Também verificaram a superioridade dos híbridos em relação ao genitor superior para os caracteres peso médio do fruto, em ní- 
veis de $71,73 \%, 8,36 \%$ e $78,81 \%$ em cada trabalho; e, para o comprimento do fruto, de $29,03 \%, 15,67 \%$ e $64,80 \%$, respectivamente. Os maiores valores de heterobeltiose foram constatados por Ahmed \& Muzafar Hurra (2000), Mamedov \& Pyshnaja (2001) e Doshi et al. (2001) para produção total de frutos em níveis máximos de 174,52\%, $181,2 \%$ e $77,9 \%$, respectivamente.

Melo (1997) estimou valores elevados de heterobeltiose em pimentão para os componentes de produção total de frutos por planta (atingindo valor máximo 46,07\%); peso dos frutos da produção precoce (154,74\%); e número de frutos da produção precoce (com valor máximo de 192,31\%).

Da Silva (2002) observou que a heterose em relação a média dos parentais manifestou-se principalmente nos caracteres altura de planta na maturidade, produção de frutos por planta, número de frutos por planta, peso médio do fruto, comprimento do fruto e espessura de pericarpo do fruto. Além desses caracteres, a heterose padrão se destacou para diâmetro do fruto e número de lóculos por fruto. Já a heterobeltiose foi detectada apenas para comprimento e peso médio de fruto.

Tem-se relatos de muitos estudos em híbridos duplos de milho e aspargo devido a vantagens, como maior produtividade. Porém, em pimentão, estudos consistentes são restritos, possivelmente em função do incremento no custo de produção e da maior desuniformidade nos híbridos duplos. Essas desvantagens poderiam ser superadas com a alta heterose apresentada em alguns híbridos duplos bem como pela incorporação de resistência a doenças, precocidade, qualidade dos frutos; além do menor custo de vendas das sementes em função da maior produção de sementes, se comparado a dos híbridos simples.

Para verificar o potencial de superioridade de híbridos duplos de pimentão em relação aos progenitores, este trabalho teve por objetivos a obtenção de híbridos duplos a partir de cruzamentos entre cinco híbridos simples, e a avaliação desses e seus progenitores, por meio da estimativa da heterose em relação à médias dos progenitores, bem como do progenitor superior e do híbri- do padrão.

\section{MATERIAL E MÉTODOS}

O experimento foi conduzido em túnel de plástico alto pertencente à FCAV-UNESP, Jaboticabal, SP, de setembro de 1997 a janeiro de 1999.

Cinco híbridos simples, (1) Magali R, (2) BGJ-27, (3) BGJ-28, (4) BGJ-29 e (5) BGJ-30 (Blat, 1999) foram usados nos cruzamentos para obtenção de 10 híbridos duplos: 1x2, 1x3, 2x3, 2x4, 3x4, 3x5, 4x5, 4x1, 5x1, 5x2.

Magali R é considerado híbrido padrão comercial, possui frutos cônicos, de 12 a 15 cm de comprimento por 8 a 9 cm de largura, com 220 a 240 g sendo vermelhos quando maduros. A colheita se inicia aos 100-110 dias após a semeadura. Possui resistência a Phytophthora capsici; BGJ-27 é um híbrido experimental do banco de germoplasma da FCAV-UNESP, possui frutos retangulares de 185 g, 3 a 4 lóculos e vermelhos quando maduros. Possui resistência ao TMV, PVY e TEV; BGJ-28 é híbrido experimental do banco de germoplasma da FCAV-UNESP, possui frutos retangulares de 14 a $16 \mathrm{~cm}$ de comprimento por 8 a 10 cm de largura, têm 4 lóculos, peso médio de 200 a $240 \mathrm{~g}$ e amarelos quando maduros. A colheita se inicia entre 130 e 150 dias após a semeadura. Possui resistência a TMV, PVY e TEV; BGJ-29 é híbrido experimental do banco de germoplasma da FCAV-UNESP, possui frutos cilíndricos, coloração verde escura brilhante, peso médio de 240 g, frutos grandes, com início de colheita entre 100-110 dias. Possui resistência a Phytophthora capsici; BGJ-30 é híbrido experimental do banco de germoplasma da FCAV-UNESP, possui frutos retangulares de 13 a $14 \mathrm{~cm}$ de comprimento por $10 \mathrm{~cm}$ de largura, peso médio entre 180 e 220 g, tornando-se vermelhos quando maduros. A colheita se inicia entre 130 e 150 dias após a semeadura. Possui tolerância a Phytophthora capsici.

As mudas foram produzidas em bandejas de poliestireno expandido e transplantadas para canteiros de 48,5 m de comprimento, 0,80 m de largura e 0,20 m de altura. Cada parcela experimental constou de uma linha de oito plantas de cada tratamento no espaçamento de 1,6 x 0,4 m. O delineamento experimental foi blocos casualizados com três repetições e 15 tratamentos, sendo cinco híbridos simples e 10 híbridos duplos.

Os cruzamentos foram realizados por meio de emasculação e polinização nas horas mais frescas do dia. Os tratos culturais foram os tradicionais para a cultura de estufa, sendo irrigação por gotejamento, tutoramento por espaldeira dupla e controle de pragas e doenças de acordo com as necessidades. Foi retirada a primeira flor da bifurcação e não foi realizada qualquer tipo de poda, sendo somente retiradas as folhas mais velhas da base da planta visando eliminar foco de doenças. A adubação de plantio foi feita de acordo com a análise de solo, utilizando-se 5,90 kg de nitrocálcio, 26,0 kg de superfosfato simples, $6 \mathrm{~kg}$ de cloreto de potássio e 267 g de bórax por 295,25 m² de área. Foi feita também adubação de cobertura parcelada em seis aplicações, utilizando-se 23,6 g de nitrocálcio e 8,8 g de cloreto de potássio por planta.

Os frutos foram colhidos maduros e avaliados os caracteres: número de dias para o florescimento (até a abertura da primeira flor de cada planta por parcela), peso do fruto (média de 10 frutos por parcela), produtividade (avaliada em cinco plantas úteis da parcela em $\mathrm{kg} / \mathrm{m}^{2}$ ), comprimento e largura do fruto (uso de paquímetro em 10 frutos por parcela), número de lóculos por fruto (razão entre o número de frutos e de lóculos), espessura de polpa (uso de paquímetro em 10 frutos por parcela), firmeza do fruto (em 10 frutos por parcela, mediante escala de notas em análise sensorial, sendo 1=muito firme, 2=firme, 3=pouco firme), e altura da planta (da região do coleto até o ápice da planta, em cinco plantas por parcela), conforme preconizado por Blat (1999).

Nas avaliações, as médias foram obtidas de cinco plantas por parcela e para frutos, de 10 frutos maduros por parcela. Foram colhidos os 10 primeiros frutos por planta nas diferentes colheitas. Os valores estimados das unidades experimentais para cada caráter avaliado foram utilizados em análise de variância para obter a significância da estatística F e, as médias, analisadas pelo teste de Tukey em 5\% de probabilidade. 
Tabela 1. Médias de dias para o florescimento, peso do fruto e produtividade e valores de heterose relativa em híbridos de pimentão (average days to flowering, yield and weight of fruits and heterosis values in relation to sweet pepper hybrids). Jaboticabal, UNESP, 1997/1999.

\begin{tabular}{|c|c|c|c|c|c|c|c|c|c|c|c|c|}
\hline \multirow{3}{*}{ Híbridos } & \multicolumn{4}{|c|}{ Dias para o florescimento } & \multicolumn{4}{|c|}{ Peso do fruto } & \multicolumn{4}{|c|}{ Produtividade } \\
\hline & \multirow{2}{*}{$\begin{array}{c}\text { Médias* } \\
\text { (dias) }\end{array}$} & \multicolumn{3}{|c|}{ Heterose relativa } & \multirow{2}{*}{$\begin{array}{l}\text { Médias* } \\
\text { (g) }\end{array}$} & \multicolumn{3}{|c|}{ Heterose relativa } & \multirow{2}{*}{$\begin{array}{l}\text { Médias* } \\
\text { (kg) }\end{array}$} & \multicolumn{3}{|c|}{ Heterose relativa } \\
\hline & & Hmp ${ }^{1}$ & $\mathrm{Hps}^{2}$ & $\mathrm{Hhp}^{3}$ & & $\mathrm{Hmp}^{1}$ & $\mathrm{Hps}^{2}$ & $\mathrm{Hhp}^{3}$ & & Hmp ${ }^{1}$ & $\mathrm{Hps}^{2}$ & $\mathrm{Hhp}^{3}$ \\
\hline Magali $R(1)$ & $104,25 \mathrm{abcd}$ & - & - & 0,00 & $247,17 b$ & - & - & 0,00 & $10,00 a$ & - & - & 0,00 \\
\hline BGJ-27 (2) & $99,29 \mathrm{e}$ & - & - & $-4,76$ & $303,49 a b$ & - & - & 22,79 & $8,56 a b c d$ & - & - & $-14,40$ \\
\hline BGJ-28 (3) & $100,60 \mathrm{de}$ & - & - & $-3,50$ & $296,63 a b$ & - & - & 20,01 & $7,99 \mathrm{abcde}$ & - & - & $-20,10$ \\
\hline BGJ-29 (4) & $105,00 \mathrm{abcd}$ & - & - & 0,72 & $240,47 b$ & - & - & $-2,71$ & $5,79 \mathrm{e}$ & - & - & $-42,10$ \\
\hline BGJ-30 (5) & $102,87 a b c d e$ & - & - & $-1,32$ & $247,28 b$ & - & - & 0,04 & $6,68 \mathrm{de}$ & - & - & $-33,20$ \\
\hline $1 \times 2$ & $104,37 a b c d$ & 2,55 & 5,12 & 0,12 & $290,89 a b$ & 5,65 & $-4,15$ & 17,69 & $7,44 \mathrm{cde}$ & $-19,83$ & $-25,60$ & $-25,60$ \\
\hline $1 \times 3$ & $107,41 a$ & 4,87 & 6,80 & 3,03 & $261,10 a b$ & $-3,97$ & $-11,98$ & 5,64 & $7,80 \mathrm{abcde}$ & $-13,29$ & $-22,00$ & $-22,00$ \\
\hline $2 \times 3$ & $102,66 \mathrm{bcde}$ & 2,72 & 3,39 & $-1,53$ & $298,99 a b$ & $-0,36$ & $-1,48$ & 20,97 & $7,58 \mathrm{cde}$ & $-8,40$ & $-11,45$ & $-24,20$ \\
\hline $2 \times 4$ & $104,49 a b c d$ & 2,30 & 5,24 & 0,23 & $291,91 \mathrm{ab}$ & 7,33 & $-3,82$ & 18,10 & $9,97 a b$ & 38,95 & 16,47 & $-0,30$ \\
\hline $3 \times 4$ & $101,62 \mathrm{cde}$ & $-1,15$ & $-1,74$ & $-2,52$ & $309,65 a b$ & 15,30 & 4,39 & 25,28 & $8,80 \mathrm{abcd}$ & 27,72 & 10,14 & $-12,00$ \\
\hline $3 \times 5$ & $98,50 \mathrm{e}$ & $-3,18$ & $-2,09$ & $-5,52$ & $305,30 a b$ & 12,26 & 2,92 & 23,52 & $7,75 \mathrm{bcde}$ & 5,66 & $-3,00$ & $-22,50$ \\
\hline $4 \times 5$ & $107,46 a$ & 3,39 & 4,46 & 3,08 & $325,93 a$ & 33,65 & 31,81 & 31,86 & $8,29 a b c d$ & 32,96 & 24,10 & $-17,10$ \\
\hline $4 \times 1$ & $106,03 \mathrm{abc}$ & 1,34 & 1,71 & 1,71 & $260,11 a b$ & 6,68 & 5,24 & 5,24 & $9,37 a b c$ & 18,68 & $-6,30$ & $-6,30$ \\
\hline $5 \times 1$ & $105,56 \mathrm{abc}$ & 1,93 & 2,61 & 1,26 & $241,50 b$ & $-2,32$ & $-2,34$ & $-2,29$ & $7,90 \mathrm{abcde}$ & $-5,28$ & $-21,00$ & $-21,00$ \\
\hline $5 \times 2$ & $106,69 a b$ & 5,55 & 7,45 & 2,34 & $278,59 a b$ & 1,16 & $-8,20$ & 12,71 & $7,05 \mathrm{cde}$ & $-7,48$ & $-17,64$ & $-29,50$ \\
\hline $\mathrm{CV}(\%)$ & 1,50 & & & & 9,02 & & & & 9,50 & & & \\
\hline
\end{tabular}

${ }^{1} \mathrm{Hmp}$ : heterose em relação à média dos progenitores; ${ }^{2} \mathrm{Hps}$ : ao progenitor superior; ${ }^{3} \mathrm{Hhp}$ : ao híbrido padrão $\left({ }^{1} \mathrm{Hmp}\right.$ : heterosis related to the average values of the parents; ${ }^{2} \mathrm{Hps}$ : related to the superior parent; ${ }^{3} \mathrm{Hhp}$ : related to the standard hybrid); *Médias seguidas da mesma letra na coluna, não diferem significativamente, pelo teste de Tukey em nível de $5 \%$ de probabilidade (means followed by the same letter in the column did not differ from each other, Tukey, 5\%).

As estimativas das heteroses foram calculadas em relação a média dos progenitores, do progenitor superior e do híbrido padrão (Magali R) com fulcro nas seguintes expressões: tores

a) em relação a média dos progeni-

Hmp (\%) $=[(\mathrm{h}-\mathrm{MP}) / \mathrm{MP}] \times 100$ sendo, $\mathrm{MP}=(\mathrm{P} 1+\mathrm{P} 2) / 2$

b) em relação ao progenitor superior

Hps $(\%)=[(\mathrm{h}-\mathrm{P}) / \mathrm{P}] \times 100$

c) em relação ao híbrido padrão

Hhp $(\%)=[(\mathrm{h}-\mathrm{HP}) / \mathrm{HP}] \times 100$,

em que: $\mathrm{H}=$ heterose; $\mathrm{h}=$ desempenho do híbrido duplo; $\mathrm{MP}=$ média dos progenitores; P1 e P2 = desempenho de cada um dos progenitores; $\mathrm{P}=$ desempenho do melhor progenitor; e HP = desempenho do híbrido padrão.

\section{RESULTADOS E DISCUSSÃO}

Para o número médio de dias para o florescimento, apenas os híbridos duplos $3 \times 4$ e $3 \times 5$ se destacaram com maior precocidade, com heteroses negativas, em relação à média dos parentais, ao parental superior e ao híbrido padrão. A heterose negativa, no caso, indica me- nor número de dias para o florescimento e, conseqüentemente, produção mais precoce. Esses resultados estão de acordo com as considerações de Melo (1997) e Tavares \& Maluf (1994) avaliando o mesmo caráter em híbridos simples. Os híbridos simples 2, 3 e 5 também apresentaram-se mais precoces em relação ao padrão Magali R (Tabela 1).

O híbrido duplo $4 \times 5$ foi um dos que apresentou maior peso médio de fruto (325,93g), embora tenha diferido significativamente apenas do híbrido duplo 5x1 e dos híbridos simples 5, 1 e 4. Esse híbrido apresentou alta heterose tanto em relação à média dos parentais quanto ao parental superior e ao híbrido padrão, com 33,65\%, 31,81\% e 31,86\%, respectivamente. Para o caráter, sete dos dez híbridos duplos foram superiores em heterose em relação à média de seus parentais, enquanto em relação ao parental superior quatro híbridos foram superiores, estando de acordo com Ahmed \& Muzafar Hurra (2000), Doshi \& Shukla (2000), Kumar \& Lal (2001) e Da Silva (2002), em avaliações de híbridos simples. A heterose de maior destaque foi em relação ao híbrido padrão. Com exceção do híbrido duplo 5x1 e do híbrido simples 4 , todos os demais mostraram-se mais vigorosos em relação ao híbrido líder de mercado, Magali R. Estes resultados estão de acordo com as considerações feitas por Innecco (1995), Braz (1982) e Melo (1997) (Tabela 1).

Para o caráter produtividade, nenhum híbrido apresentou heterose positiva em relação ao híbrido padrão, embora seis dos 10 híbridos duplos não diferiram significativamente em produtividade média da mesma. Para o caráter, os híbridos duplos 2x4, 3x4 e 4x5 destacaram-se pela positiva e elevada heterose em relação a média dos parentais e ao parental superior, estando de acordo com resultados obtidos por Ahmed \& Muzafar Hurra (2000), Mamedov \& Pyshnaja (2001) e Doshi et al. (2001) (Tabela 1).

O comprimento e a largura dos frutos (tamanho do fruto) são características importantes na comercialização de frutos de pimentão, uma vez que o mercado brasileiro valoriza frutos grandes. Houve diferença entre os híbridos para comprimento médio do fruto, indicando a variabilidade entre os mesmos. De modo geral todos os híbridos apresentaram frutos de tamanho médio a gran- 
Tabela 2. Médias de comprimento do fruto, largura do fruto e número de lóculos e valores de heterose relativa em híbridos de pimentão (average fruit lenght, width and number of locules and relative heterosis values from sweet pepper hybrids). Jaboticabal, UNESP, 1997/1999.

\begin{tabular}{|c|c|c|c|c|c|c|c|c|c|c|c|c|}
\hline \multirow{3}{*}{ Híbridos } & \multicolumn{4}{|c|}{ Comprimento do fruto } & \multicolumn{4}{|c|}{ Largura do fruto } & \multicolumn{4}{|c|}{ Número de lóculos } \\
\hline & \multirow{2}{*}{$\begin{array}{l}\text { Médias* } \\
\text { (cm) }\end{array}$} & \multicolumn{3}{|c|}{ Heterose relativa } & \multirow{2}{*}{$\begin{array}{c}\text { Médias* } \\
(\mathrm{cm})\end{array}$} & \multicolumn{3}{|c|}{ Heterose relativa } & \multirow{2}{*}{$\begin{array}{c}\text { Médias* } \\
\left(n^{\circ}\right)\end{array}$} & \multicolumn{3}{|c|}{ Heterose relativa } \\
\hline & & $\mathrm{Hmp}^{1}$ & $\mathrm{Hps}^{2}$ & $\mathrm{Hhp}^{3}$ & & $\mathrm{Hmp}^{1}$ & $\mathrm{Hps}^{2}$ & $\mathrm{Hhp}^{3}$ & & $\mathrm{Hmp}^{1}$ & $\mathrm{Hps}^{2}$ & Hhp $^{3}$ \\
\hline Magali $R(1)$ & $15,75 \mathrm{ab}$ & - & - & 0,00 & $7,09 \mathrm{bc}$ & - & - & 0,00 & $3,30 a$ & - & - & 0,00 \\
\hline BGJ-27 (2) & $13,26 \mathrm{~cd}$ & - & - & $-15,81$ & $8,13 a$ & - & - & 14,67 & $3,73 a$ & - & - & 10,03 \\
\hline BGJ-28 (3) & $13,98 \mathrm{abcd}$ & - & - & $-11,24$ & $7,55 a b c$ & - & - & 6,49 & $3,77 a$ & - & - & 14,24 \\
\hline BGJ-29 (4) & $14,44 \mathrm{abcd}$ & - & - & $-8,32$ & $6,75 \mathrm{c}$ & - & - & $-4,80$ & $3,63 a$ & - & - & 10,00 \\
\hline BGJ-30 (5) & $12,77 \mathrm{~d}$ & - & - & $-18,92$ & $7,60 \mathrm{abc}$ & - & - & 7,19 & $3,57 a$ & - & - & 8,18 \\
\hline $1 \times 2$ & $14,36 a b c d$ & $-1,00$ & $-8,83$ & $-8,83$ & $7,96 a b$ & 4,60 & $-2,09$ & 12,27 & $3,43 a$ & $-2,42$ & $-8,04$ & 3,94 \\
\hline $1 \times 3$ & $14,35 \mathrm{abcd}$ & $-3,46$ & $-8,89$ & $-8,89$ & $7,50 \mathrm{abc}$ & 2,46 & $-0,66$ & 5,78 & $3,63 a$ & 2,69 & $-3,71$ & 10,00 \\
\hline $2 \times 3$ & $13,74 \mathrm{bcd}$ & 0,98 & $-1,72$ & $-12,76$ & $8,03 a b$ & 2,42 & $-1,23$ & 13,26 & $3,47 a$ & $-7,47$ & $-7,96$ & 5,15 \\
\hline $2 \times 4$ & $13,45 \mathrm{~cd}$ & $-2,89$ & $-6,86$ & $-14,60$ & $8,03 a b$ & 7,93 & $-1,23$ & 13,26 & $3,73 a$ & 1,36 & 0,00 & 13,03 \\
\hline $3 \times 4$ & $15,04 \mathrm{abc}$ & 5,84 & 4,16 & $-4,51$ & $7,92 a b$ & 10,77 & 4,90 & 11,71 & $3,63 a$ & $-1,89$ & $-3,71$ & 10,00 \\
\hline $3 \times 5$ & $13,97 \mathrm{abcd}$ & 4,45 & $-0,07$ & $-11,30$ & $7,84 a b$ & 3,50 & 3,16 & 10,58 & $3,83 a$ & 4,36 & 1,59 & 16,06 \\
\hline $4 \times 5$ & $14,97 a b c$ & 10,03 & 3,67 & $-4,95$ & $7,80 \mathrm{ab}$ & 8,71 & 2,63 & 10,01 & $3,57 a$ & $-0,83$ & $-1,65$ & 8,18 \\
\hline $4 \times 1$ & $15,96 a$ & 5,73 & 1,33 & 1,33 & $7,14 \mathrm{bc}$ & 3,18 & 0,71 & 0,71 & $3,43 a$ & $-1,01$ & $-5,51$ & 3,94 \\
\hline $5 \times 1$ & $13,97 \mathrm{abcd}$ & $-2,03$ & $-11,30$ & $-11,30$ & $7,16 a b c$ & $-2,52$ & $-5,79$ & 0,99 & $3,67 a$ & 6,84 & 2,80 & 11,21 \\
\hline $5 \times 2$ & $12,49 d$ & $-4,03$ & $-5,81$ & $-20,70$ & $7,80 \mathrm{ab}$ & $-0,83$ & $-4,06$ & 10,01 & $3,67 a$ & 0,55 & $-6,61$ & 11,21 \\
\hline CV (\%) & 4,94 & & & & 4,26 & & & & 7,24 & & & \\
\hline
\end{tabular}

${ }^{1}$ Hmp: heterose em relação à média dos progenitores; ${ }^{2} \mathrm{Hps}$ : ao progenitor superior; ${ }^{3} \mathrm{Hhp}$ : ao híbrido padrão $\left({ }^{1} \mathrm{Hmp}\right.$ : heterosis related to the average values of the parents; ${ }^{2} \mathrm{Hps}$ : related to the superior parent; ${ }^{3} \mathrm{Hhp}$ : related to the standard hybrid) * Médias seguidas da mesma letra, na coluna, não diferem significativamente, pelo teste de Tukey em nível de $5 \%$ de probabilidade (means followed by the same letter in the column did not differ from each other, Tukey, 5\%).

de, variando de 12,49 a $15,96 \mathrm{~cm}$. Concordando com as considerações de Tavares \& Maluf (1994), a heterose em relação à média dos parentais foi positiva manifestando-se em cinco dos 10 híbridos duplos. Porém esse grau de heterose foi baixo, sendo que o híbrido $4 \times 5$ apresentou o valor mais elevado, $10,03 \%$. As heteroses em relação ao parental superior e ao híbrido padrão foram baixas e manifestaram-se em apenas três híbridos duplos em relação ao parental superior e em um (4x1) em relação ao híbrido padrão. A pequena heterose para esse caráter pode ser explicada pela herança qualitativa do caráter e pela dominância para menor tamanho de fruto (Mcardle \& Bouwkamp, 1983).

O híbrido duplo $4 \times 5$, assim como para o caráter comprimento médio do fruto, foi um dos que obteve a maior heterose para largura média do fruto, $8,71 \%$, tendo apenas heterose menor que o híbrido duplo $3 \times 4$ com $10,77 \%$. O maior destaque foi para a heterose em relação ao híbrido padrão Magali R, em que, com exceção do híbrido simples 4, todos os demais foram superiores ao padrão (Tabela 2).
O número de lóculos depende do número de carpelos e está diretamente relacionado com o formato do fruto. As médias para número de lóculos, não diferiram entre si, estando de acordo com as considerações de Braz (1982) em sua avaliação em híbridos simples. Mesmo assim, a heterose manifestou-se nos híbridos duplos tanto em relação à média dos parentais, ao parental superior, quanto em relação ao híbrido padrão. Em relação à média dos parentais e ao parental superior, as heteroses foram baixas, destacando-se o híbrido $5 \times 1$ com $6,84 \%$ e $2,80 \%$, respectivamente. Já em relação ao híbrido padrão, embora os valores de heterose não tenham sido elevados, destacou-se o híbrido 3x5 com $16,06 \%$. Isso se deve ao fato do híbrido padrão Magali R ter apresentado o menor número médio de lóculos. Esse híbrido também apresentou a maior espessura de polpa. Esses resultados informam que todos os híbridos duplos tiveram maior número de lóculos que o híbrido líder de mercado, Magali R (Tabela 2).

A espessura de polpa está vinculada à qualidade do fruto e à produtividade. Uma cultivar com espessura de polpa grossa tem duas principais vantagens: frutos mais pesados, podendo ser comercializados por peso e não por volume e maior conservação pós-colheita, pois o processo de murchamento é menos acentuado (Blat, 1999). Embora não tenha havido diferenças significativas entre os híbridos para o caráter, as heteroses tanto em relação à média dos parentais quanto ao híbrido padrão Magali $\mathrm{R}$, foram positivas para seis dos 10 híbridos duplos, destacando-se principalmente os híbridos $3 \times 4$ e 3x5. Esses híbridos, principalmente o 3x4, também apresentaram elevada heterose para peso médio e firmeza do fruto (Tabela 3). Para esse caráter os dados estão de acordo com os obtidos por Da Silva (2002).

A firmeza do fruto é um caráter de grande importância, pois quanto mais firme o fruto, menores as perdas causadas por danos físicos durante o manuseio pós-colheita. O híbrido duplo $2 \mathrm{x} 4$ apresentou-se entre os mais firmes. Com exceção do híbrido duplo 3x5, os demais apresentaram heterose altamente negativa para o caráter, o que é interessante, pois mostra a superioridade em firmeza em relação à média dos seus parentais, ao parental superior e ao híbrido padrão (Tabela 3). 
Tabela 3. Médias de espessura de polpa, firmeza do fruto e peso da matéria fresca da placenta e valores de heterose relativa em híbridos de pimentão (average flesh thickness, fruit firmness and fresh matter weight of placenta and, relative heterosis values from sweet pepper hybrids). Jaboticabal, UNESP, 1997/1999.

\begin{tabular}{|c|c|c|c|c|c|c|c|c|c|c|c|c|}
\hline \multirow{3}{*}{ Híbridos } & \multicolumn{4}{|c|}{ Espessura de polpa } & \multicolumn{4}{|c|}{ Firmeza do fruto } & \multicolumn{4}{|c|}{ Altura da planta } \\
\hline & \multirow{2}{*}{$\begin{array}{c}\text { Médias* } \\
(\mathrm{mm})\end{array}$} & \multicolumn{3}{|c|}{ Heterose relativa } & \multirow{2}{*}{$\begin{array}{c}\text { Médias* } \\
\text { (notas) }\end{array}$} & \multicolumn{3}{|c|}{ Heterose relativa } & \multirow{2}{*}{$\begin{array}{l}\text { Médias* } \\
(\mathrm{m})\end{array}$} & \multicolumn{3}{|c|}{ Heterose relativa } \\
\hline & & $\mathrm{Hmp}^{1}$ & $\mathrm{Hps}^{2}$ & $\mathrm{Hhp}^{3}$ & & $\mathrm{Hmp}^{1}$ & $\mathrm{Hps}^{2}$ & $\mathrm{Hhp}^{3}$ & & $\mathrm{Hmp}^{1}$ & $\mathrm{Hps}^{2}$ & Hhp $^{3}$ \\
\hline Magali R (1) & $4,68 a$ & - & - & 0,00 & $1,73 a b$ & - & - & 0,00 & 1,95ab & - & - & 0,00 \\
\hline BGJ-27 (2) & $5,03 a$ & - & - & 7,48 & $1,47 a b$ & - & - & $-15,03$ & $1,55 \mathrm{de}$ & - & - & $-20,51$ \\
\hline BGJ-28 (3) & $4,88 a$ & - & - & 4,27 & $1,43 a b$ & - & - & $-17,34$ & $1,74 a b c d e$ & - & - & $-10,77$ \\
\hline BGJ-29 (4) & $4,34 a$ & - & - & $-7,28$ & $2,10 a$ & - & - & 21,39 & $1,72 \mathrm{abcde}$ & - & - & $-11,80$ \\
\hline BGJ-30 (5) & $4,45 a$ & - & - & $-4,92$ & $2,10 a$ & - & - & 21,39 & $1,90 \mathrm{abc}$ & - & - & $-2,56$ \\
\hline $1 \times 2$ & $4,85 a$ & $-0,10$ & $-3,58$ & 3,63 & $1,43 a b$ & $-10,62$ & $-2,72$ & $-17,34$ & $1,71 \mathrm{abcde}$ & $-2,29$ & $-12,31$ & $-12,31$ \\
\hline $1 \times 3$ & $4,43 a$ & $-7,32$ & $-9,22$ & $-5,34$ & $1,63 a b$ & 3,16 & 13,99 & $-5,78$ & 1,71abcde & $-7,32$ & $-12,31$ & $-12,31$ \\
\hline $2 \times 3$ & $5,00 a$ & 0,91 & $-0,60$ & 6,84 & $1,37 a b$ & $-5,52$ & $-4,20$ & $-20,81$ & $1,63 \mathrm{bcde}$ & $-0,91$ & $-6,32$ & $-16,41$ \\
\hline $2 \times 4$ & $4,91 a$ & 4,80 & $-2,39$ & 4,91 & $1,13 b$ & $-36,69$ & $-23,13$ & $-34,68$ & 1,70abcde & 3,98 & $-1,16$ & $-12,82$ \\
\hline $3 \times 4$ & $5,00 a$ & 8,46 & 2,46 & 6,84 & $1,23 a b$ & $-30,31$ & $-13,99$ & $-28,90$ & $1,52 e$ & $-12,14$ & $-12,64$ & $-22,05$ \\
\hline $3 \times 5$ & $5,01 a$ & 7,40 & 2,66 & 7,05 & $2,00 a b$ & 13,31 & 39,86 & 15,51 & $1,87 \mathrm{abcd}$ & 2,75 & $-1,58$ & $-4,10$ \\
\hline $4 \times 5$ & $4,69 a$ & 6,71 & 5,39 & 0,21 & $1,87 a b$ & $-10,95$ & $-10,95$ & 8,09 & $1,57 \mathrm{cde}$ & $-13,26$ & $-17,37$ & $-19,49$ \\
\hline $4 \times 1$ & $4,50 a$ & $-0,22$ & $-3,85$ & $-3,85$ & $1,63 a b$ & $-14,88$ & $-5,78$ & $-5,78$ & $1,88 \mathrm{abc}$ & 2,45 & $-3,59$ & $-3,59$ \\
\hline $5 \times 1$ & $4,11 \mathrm{a}$ & $-9,97$ & $-12,18$ & $-12,18$ & $1,63 a b$ & $-14,88$ & $-5,78$ & $-5,78$ & $2,02 a$ & 4,94 & 3,59 & 3,59 \\
\hline $5 \times 2$ & $4,85 a$ & 2,32 & $-3,58$ & 3,63 & $1,37 a b$ & $-23,25$ & $-6,80$ & $-20,81$ & $1,80 \mathrm{abcde}$ & 4,35 & $-5,26$ & $-7,69$ \\
\hline CV (\%) & 6,55 & & & & 18,51 & & & & 6,21 & & & \\
\hline
\end{tabular}

${ }^{1} \mathrm{Hmp}$ : heterose em relação à média dos progenitors; ${ }^{2} \mathrm{Hps}$ : ao progenitor superior; ${ }^{3} \mathrm{Hhp}$ : a híbridor padrão ( ${ }^{1} \mathrm{Hmp}$ : heterosis related to the average values of the parents; ${ }^{2} \mathrm{Hps}$ : related to the superior parent; ${ }^{3} \mathrm{Hhp}$ : related to the standard hybrid);. * Médias seguidas da mesma letra, na coluna, não diferem significativamente, pelo teste de Tukey em nível de 5\% de probabilidade (means followed by the same letter in the column did not differ from each other, Tukey, 5\%).

Os resultados de altura da planta mostraram que as plantas dos híbridos duplos apresentaram uma altura igual ou inferior a dos seus progenitores. Se uma planta obtiver uma mesma produção é interessante que ela tenha um porte médio, até cerca de $2,00 \mathrm{~m}$, pois facilitaria os tratos culturais e a colheita de frutos. Com relação ao grau de heterose, os híbridos se destacaram principalmente em relação ao parental superior e ao híbrido padrão, sendo a heterose negativa, o que indica que as plantas desses híbridos tiveram a altura menor que o parental superior e o híbrido padrão.

Embora o híbrido padrão tenha revelado a maior produtividade, demonstrou muitos aspectos negativos com relação aos híbridos duplos, como um maior número de dias para o florescimento, indicando ser tardio, com menor largura de fruto e número de lóculos, uma das menores espessuras de polpa e, conseqüentemente, firmeza de fruto, além de uma das maiores alturas da planta.

\section{AGRADECIMENTOS}

à FAPESP pelo suporte financeiro e bolsa de mestrado.

\section{REFERÊNCIAS}

AHMED DN; HURRA M. 2000. Heterosis studies for fruit yield and some economic characters in sweet peppers (Capsicum annuum L.). Capsicum and Eggplant Newsletter 19: 74-77.

BLAT SF. 1999. Obtenção e avaliação de híbridos duplos de pimentão (Capsicum annuum L.). Jaboticabal: FCAV - UNESP. 74p (Dissertação mestrado).

BRAZ LT. 1982. Avaliação de caracteres agronômicos e qualitativos de três cultivares de pimentão (Capsicum annuum L.) e da heterose em seus híbridos $F_{1}$. Viçosa: UFV. 75p (Dissertação mestrado).

CNPH, Projeto Capsicum. Embrapa Hortaliças. 2001. http://www.cnph.embrapa.br/projetos/ capsicum/index.html.

DA SILVA LL. 2002. Heterose e capacidade de combinação em cruzamentos dialélicos parciais de pimentão. Piracicaba: USP - ESALQ. 82p (Dissertação mestrado).
DOSHI KM; SHUKLA PT. 2000. Expression of heterosis in chilli (Capsicum annuum L.). Capsicum and Eggplant Newsletter .19: 66-69.

DOSHI KM; SHUKLA MK; KATHIRIA KB. 2001. Seedling analysis for the prediction of heterosis and combining ability in chilli (Capsicum annuum L.). Capsicum and Eggplant Newsletter. 20: 46-49.

INNECCO R. 1995. Avaliação do potencial agronômico de híbridos e capacidade combinatória de linhagens de pimentão (Capsicum annuum L.). Lavras: UFLA. 113p (Tese doutorado).

KUMAR R; LAL G. 2001. Expressions of heterosis in hot pepper (Capsicum annuum L.) Capsicum and Eggplant Newsletter 20: 38-41.

MAMEDOV MI; PYSHNAJA ON. 2001. Heterosis and correlations studies for earliness, fruit yield and some ecomonic characteristics in sweet pepper. Capsicum and eggplant newsletter 20: 42-45.

MCARDLE RN; BOUWKAMP JC. 1983. Inheritance of several fruit characters in Capsicum annuum L. Journal of Heredity 74: 125-127.

MELO AMT. 1997. Análise genética de caracteres de fruto em híbridos de pimentão. Piracicaba: USP - ESALQ. 107p (Tese doutorado).

MIRANDAJEC; CASALI VWD. 1988. Métodos de melhoramento aplicados às espécies autógamas. In: SIMPÓSIO BRASILEIRO SOBRE CAPSICUM, 1. Anais... Dourados: p.15-30.

TAVARES M; MALUF WR. 1994. Vigor de híbrido na geração F1 de pimentão (Capsicum annuum L.). Ciência e Prática 18: 171-177. 